\title{
Effects of hydration on molecular mobility in phase-bright Bacillus subtilis spores
}

\author{
Renata G. K. Leuschner† and Peter J. Lillford \\ Author for correspondence: Renata G. K. Leuschner. Tel: +44 1904 462668. Fax: +44 1904462111. \\ e-mail: r.leuschner@csl.gov.uk
}

Unilever Research Colworth, Sharnbrook MK44 1LQ, UK

\begin{abstract}
The molecular mobility of ${ }^{31} \mathrm{P}$ and ${ }^{13} \mathrm{C}$ in dormant Bacillus subtilis spore samples with different water concentrations was investigated by high-resolution solidstate NMR. Lowest molecular mobility was observed in freeze-dried preparations. Rehydration to a $10 \%$ weight increase resulted in increases in molecular motions and addition of excess water furthered this effect. A spore slurry which had been freeze-dried displayed after addition of excess water similar NMR spectra to native wet preparations. Dipicolinic acid (DPA), which is mainly located in the core, was detected at all hydration levels in ${ }^{13} \mathrm{C}$ crosspolarization magic angle spinning (CPMAS) but not in single-pulse magic angle spinning (SPMAS) spectra, indicating that hydration had no effect on its mobility. The molecular mobility of ${ }^{31} \mathrm{P}$, present mainly in core-specific components, was strongly dependent on hydration. This result suggests reversible water migration between inner spore compartments and the environment, whereas ${ }^{13} \mathrm{C}$ spectra of DPA indicate that it is immobilized in a water-insoluble network in the core. Scanning transmission electron microscopy revealed that freeze-dried spores were significantly longer and narrower than fully hydrated spores and had a $3 \%$ smaller volume.
\end{abstract}

Keywords: Bacillus subtilis, structure, NMR, hydration, spores

\section{INTRODUCTION}

Endospore formation is the ultimate example of adaptation of bacteria to starvation (Errington, 1993). Sporulation is a developmental process with an established sequence of morphological events which result in the formation of a mature, resistant spore (Moir \& Smith, 1990). Dormant spores are characterized by a complex and compartmentalized structure which consists of several layers with different morphology, chemical composition and water content (Santo \& Doi, 1974; Gould, 1977). The core of a spore is assumed to be in a low-moisture state, possibly brought about and maintained by an osmoregulatory expanded cortex (Gould \& Dring, 1974, 1975). The characteristically high heat resistance of dormant bacterial spores is explained by the low water concentration in the core

†Present address: Central Science Laboratory, Sand Hutton, York YO41 1LZ, UK.

Abbreviations: CPMAS, cross-polarization magic angle spinning; DPA, dipicolinic acid; SPMAS, single-pulse magic angle spinning; STEM, scanning transmission electron microscopy; TEM, transmission electron microscropy.
(Nakashio \& Gerhardt, 1985; Beaman \& Gerhardt, 1986; Setlow, 1994; Gaillard et al., 1998). Water contents of spore protoplasts were found to vary among Bacillus species between 26 and $55 \%$ (Nakashio \& Gerhardt, 1985; Lindsay et al., 1985; Beaman et al., 1984; Beaman \& Gerhardt, 1986). The occurrence of an insolubly gelled core with cross-linking between macromolecules through stable but reversible bonds to form a high-polymer matrix with entrapped free water was suggested by Black \& Gerhardt (1962).

NMR spectroscopy as a non-invasive technique is ideally suited to examine spore compartments without destroying cellular architecture and has been applied to investigate dormant spores. Determination and quantification of water content in spores has been extensively carried out by NMR. Vegetative cells showed narrower absorption peaks in NMR spectra than spores, indicating that water molecules in spores lack mobility in their rotational and/or exchange motions (Maeda et al., 1968). In the same study, no differences in the time course of water absorption and desorption were found between spores and vegetative cells, which suggested that immobilized water molecules could be driven off 
their sites by applying a steady force to overcome the related potential barriers in transport. Higher water mobility and water content of the core than of coat and cortex was revealed by NMR analysis (Bradbury et al., 1981). In this study, the heat resistance of spores was explained by immobilization of essential enzymes and nucleic acids by a solid support, calcium dipicolinate, similar to a charged polymer matrix.

Dipicolinic acid (DPA), a spore-specific component and present in large quantities $(5-15 \%)$, has been shown to be located mainly in the core (Murrell, 1969; Lenz \& Gilvarg, 1973; Kozuka et al., 1985). DPA seems to intercalate and to be covalently bound to macromolecules such as DNA and RNA (Matano et al., 1993; Lindsay \& Murrell, 1986). It was also found to be mainly present as CaDPA (Shibata et al., 1986). Loshon \& Setlow (1993) compared levels of small molecules in dormant Sporosarcina species with those in spores of Bacillus and Clostridium species and reported both equimolar and non-equimolar amounts of calcium and DPA. For example, spores of Bacillus subtilis contained twice and spores of Clostridium bifermentans three times the amount of $\mathrm{Ca}^{2+}$ in relation to DPA. An alphacarbon signal of DPA with a resonance at about 150 p.p.m. was identified in spores of Bacillus macerans and Bacillus cereus (Lundin \& Sacks, 1988). In ${ }^{13} \mathrm{C}$ crosspolarization magic angle spinning (CPMAS) NMR spectra, signals of immobilized carbon components appear, and crystalline and amorphous DPA display a sharp and a broad resonance peak, respectively (Ablett et al., 1999). The corresponding ${ }^{13} \mathrm{C}$ single-pulse magic angle spinning (SPMAS) NMR spectra show mobile carbon components and sharp peaks with a narrow line width indicating high mobility.

Phosphorus is concentrated in the core with more than $90 \%$ of the total amount present in a spore. The coat also contains phosphorus whereas the cortex displays only low phosphorus concentrations (Johnstone et al., 1980; Stewart et al., 1980; Nishihara et al., 1980). Significant amounts of phosphorus are contained in spores in the form of 3-phosphoglyceric acid (Loshon \& Setlow, 1993). NMR analysis of ${ }^{31} \mathrm{P}$ was shown to be meaningful in estimating the internal $\mathrm{pH}$ of bacterial spores (Shibata et al., 1984). A solid-state ${ }^{31} \mathrm{P}$ NMR study carried out by Rasmussen et al. (1997) revealed that in the ${ }^{31} \mathrm{P}$ SPMAS spectra mobile and immobile phosphorus components resonate. The mobile components can be identified by sharp peaks and the immobile components by broad resonance peaks.

In this investigation, we examined the effects of drying and rehydration of dormant spores on ${ }^{31} \mathrm{P}$ and ${ }^{13} \mathrm{C}$ molecular mobility. Changes in the size of whole dormant spores were further examined by scanning transmission electron microscopy (STEM). The objective was to obtain an insight into hydration-dependent structural changes occurring at atomic and microscopic levels in distinct compartments of B. subtilis spores.

\section{METHODS}

Bacterial strain. B. subtilis PSB 357 lux $^{+}$was provided by Dr Hill and Professor Stewart, Nottingham University, UK. The properties and application of spores of this strain as indicators for inimical processes have been described by Hill et al. (1994).

Preparation of spore suspensions. Fresh overnight cultures of B. subtilis PSB 357 lux $^{+}$were prepared by agitation at $30^{\circ} \mathrm{C}$ in heart infusion broth (Difco). Aliquots of $1 \mathrm{ml}$ were plated on heart infusion agar plates. The agar plates were incubated at $30{ }^{\circ} \mathrm{C}$ until preparations had $99 \%$ phase-bright spores as examined by phase-contrast light microscopy (Ortholux II Leitz; Leica Microsystems). Medium used for cultivation and sporulation of B. subtilis PBS $357 \mathrm{lux}^{+}$was supplemented with $150 \mu \mathrm{g}$ erythromycin $\mathrm{ml}^{-1}$ (Sigma). Spores were washed from agar plates with $10 \mathrm{ml}$ aliquots of cold, sterile distilled water. The combined suspensions were centrifuged at $4000 \mathrm{~g}$ (JLA10.500 rotor; Beckman) for $20 \mathrm{~min}$ at $4{ }^{\circ} \mathrm{C}$. The spore pellet was resuspended in distilled water and centrifuged at $4000 \mathrm{~g}$ for $30 \mathrm{~min}$ at $4{ }^{\circ} \mathrm{C}$. This washing procedure was repeated at least four to five times. Final purity and homogeneity of spore harvests were investigated as described previously (Leuschner et al., 1999). The wet spore pellet was divided into aliquots and stored at $-20{ }^{\circ} \mathrm{C}$. For this study, spores of the same spore preparation were used throughout. The viability of spores was checked at intervals throughout by plate count determination with heart infusion agar plates.

Freeze-drying and rehydration of spores. Spores were freezedried under vacuum at $4{ }^{\circ} \mathrm{C}$ (SB Multidrier, ChemLab Instruments) overnight in Eppendorf containers. These samples had no further evaporable water because heating of freeze-dried samples at $100{ }^{\circ} \mathrm{C}$ for $3 \mathrm{~h}$ was not associated with a weight loss. Rehydration of spores was carried out directly in the NMR rotor. The rotor was placed in the head space of a closed container which contained water on the bottom and was stored at $10^{\circ} \mathrm{C}$. Water uptake was measured gravimetrically. When necessary, excess water was added under stirring until a thick homogeneous slurry was obtained. Phasebrightness of spores was checked at intervals throughout the study.

NMR spectroscopy. A Bruker MSL-300 (Bruker) spectrometer system equipped with a wide-bore superconducting magnet system and a multinuclear, double-bearing $7 \mathrm{~mm}$ CPMAS VT probe (Bruker) and associated with high-power pulse amplifiers provided high-resolution solid spectra of natural abundance ${ }^{13} \mathrm{C}$ and ${ }^{31} \mathrm{P}$ at a frequency of $75.48 \mathrm{MHz}$ and 121.497 $\mathrm{MHz}$, respectively. CPMAS spectra for ${ }^{13} \mathrm{C}$ were acquired using total suppression of side bands (TOSS) (Dixon et al., 1982). Typical spectrometer conditions were a proton $\pi / 2$ excitation pulse length of $6 \mu$ s and a contact time of $1 \mathrm{~ms}$, and the resulting spectra were acquired under high-power decoupling. SPMAS spectra were obtained with a single proton $\pi / 2$ excitation pulse of $5 \cdot 5 \mu$ s and under high-power proton decoupling. Measurements were carried out using phase cycling of pulses in multipulse sequences (depth) in the manner described by Bendall \& Gordon (1983) to reduce the residual signal which comes from the probe when it is used for this type of measurement. All spore spectra were obtained at 4 or $20^{\circ} \mathrm{C}$ in a rotor (Bruker) with an outside diameter of $7 \mathrm{~mm}$, a length of $15 \mathrm{~mm}$ and a volume of $360 \mu \mathrm{l}$. An acceptable signal-tonoise ratio was usually obtained for ${ }^{13} \mathrm{C}$ after 20000 and for ${ }^{31} \mathrm{P}$ after 1000 transients. Data were acquired using the DISMSL 
software package (Bruker) for Fourier transformation. Exponential apodization, giving a line broadening of $20 \mathrm{~Hz}$ for ${ }^{13} \mathrm{C}$, was normally used. NMR spectra were referenced for ${ }^{31} \mathrm{P}$ with respect to the CPMAS spectrum of disodium hydrogen orthophosphate (FSA Laboratory Supply) at $20^{\circ} \mathrm{C}$, the resonance maximum of which was set to 0 p.p.m. This substance has a chemical shift of -3.5 when referenced against phosphoric acid (Jones \& Katritzky, 1960; Crutchfield et al., 1962), which is widely used as external reference (Dixon, 1987). ${ }^{13} \mathrm{C}$ was referenced to the standard substance Adamantane (Aldrich). RNA type XIV from herring testes, DNA type VI from Torula yeast (Sigma) and an emulsifier (Bolec Z; Unimills) to which $25 \%$ water was added were used for identification of ${ }^{31} \mathrm{P}$ resonances. The emulsifier is a mixture of phospholipids $(60 \%)$ and soya oil $(40 \%)$. It contains phosphatidylcholine, phosphatidylethanolamine, phosphatidylinositol and phosphatic acid as the four main phospholipids. Spores were transferred manually into the rotor. After each experiment their appearance by phase-contrast light microscopy and by transmission electron microscropy (TEM) was recorded to evaluate effects on their structure during NMR analysis.

Electron microscopy. All spores were generally fixed with $\mathrm{OsO}_{4}$. Freeze-dried spores were transferred into $\mathrm{CCl}_{4}(\mathrm{BDH}$ Chemicals) which had been stored over molecular sieves to absorb water. $\mathrm{CCl}_{4}$ was supplemented with $\mathrm{OsO}_{4}(1 \%, \mathrm{w} / \mathrm{v})$ (TAAB Laboratories). Hydrated spores were fixed in cacodylate buffer $\left(0.1 \mathrm{M}\right.$; TAAB Laboratories) containing $\mathrm{OsO}_{4}$ $(1 \%)$ for $2 \mathrm{~h}$.

Examination of whole spores for size determination by STEM. An aliquot of $10 \mu \mathrm{l}$ of a preserved spore suspension containing $10^{8}-10^{9}$ spores $\mathrm{ml}^{-1}$ was placed onto a carbon film supported by a 200 mesh copper grid and blotted dry. The whole spores were examined in STEM mode in a JEOL 1200 EX mk 2 transmission electron microscope. Electronic images were recorded using an ISIS $300 \mathrm{X}$-ray microanalysis and imaging system (Oxford Instruments). For size calibration, an image of a diffraction grating with 2160 lines $\mathrm{mm}^{-1}$ was used. Images were printed and the length and breadth of 60-90 spores were measured manually. ANOVA was performed using the software package SAS/Jmp (SAS Instruments). Approximately 70-90 spores were measured at a $95 \%$ level of significance $(P<0 \cdot 05)$.

Conventional TEM. For TEM examination, a pellet of preserved spores was suspended in $2 \%$ agar, cut into small pieces and then transferred into $1 \%$ aqueous uranyl acetate (TAAB Laboratories) for $3 \mathrm{~h}$. Samples were dehydrated in $70 \%, 90 \%$ and twice in absolute ethanol for $1 \mathrm{~h}$ each time. They were then held in $100 \%$ acetone (two changes for 30 min) and transferred into a mixture of $1: 1$ acetone and Araldite resin (TAAB Laboratories) overnight. Samples were kept for $24 \mathrm{~h}$ in $100 \%$ resin, transferred into fresh resin and polymerized at $60^{\circ} \mathrm{C}$ for $2 \mathrm{~d}$. Ultrathin sections were cut at 100 $\mathrm{nm}$ thickness using a Richert Ultracut E (Leica) and a diamond knife (Diatome; TAAB Laboratories). Sections were stained with Reynold's lead citrate.

\section{RESULTS}

\section{High-resolution solid-state ${ }^{31} \mathrm{P}$ NMR spectroscopy}

In the SPMAS spectrum of a native spore harvest containing excess water six peaks were identified at $-2 \cdot 5,-4,-5 \cdot 5,-7,-7 \cdot 5$ and -18 p.p.m. The
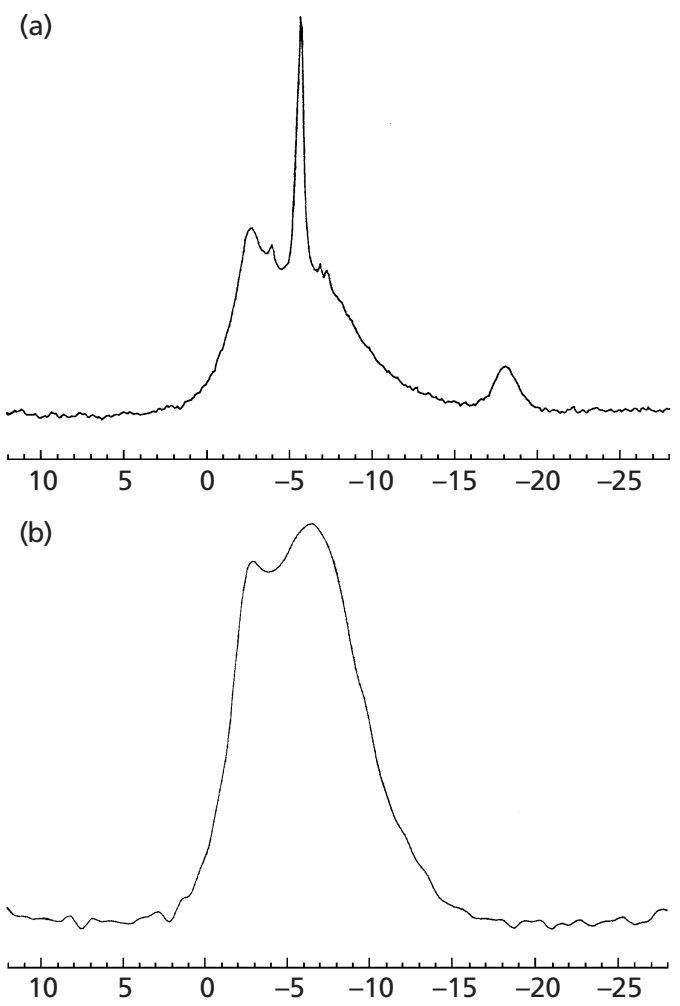

(c)

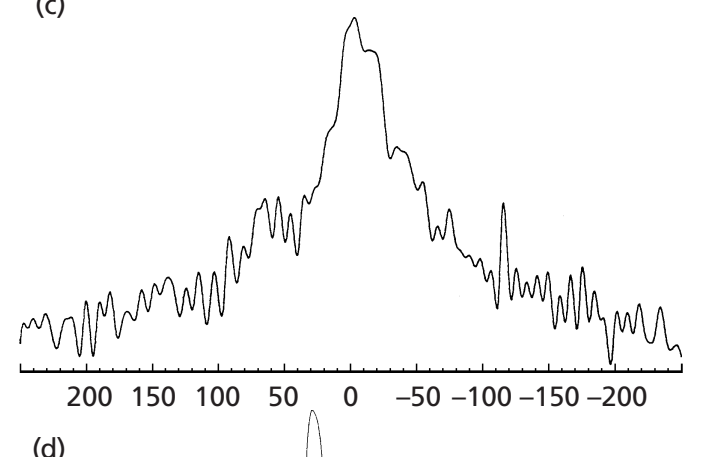

(d)

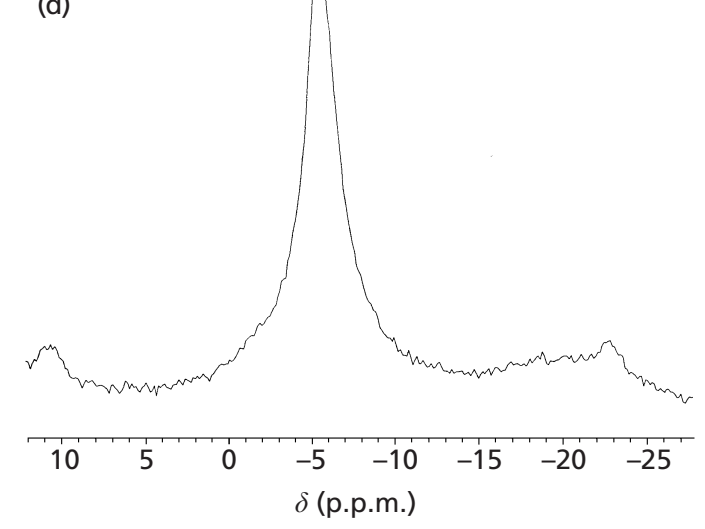

Fig. 1. ${ }^{31} \mathrm{P}$ SPMAS NMR spectrum of native, phase-bright spores of $B$. subtilis PBS 357 lux $^{+}$in excess water (a), ${ }^{31} \mathrm{P}$ CPMAS NMR spectrum of native, phase-bright spores of $B$. subtilis PBS 357 lux ${ }^{+}$in excess water (b), ${ }^{31} \mathrm{P}$ SPMAS NMR spectrum of freezedried, phase-bright spores of $B$. subtilis PBS $357 \operatorname{lux}^{+}$(c) and ${ }^{31} \mathrm{P}$ SPMAS NMR spectrum of rehydrated $(10 \%$ weight increase) freeze-dried, phase-bright spores of $B$. subtilis PBS 357 $\operatorname{lux}^{+}(\mathrm{d})$. 
Table 1. ${ }^{31} \mathrm{P}$ SPMAS and CPMAS resonances of commercial available RNA, DNA and a phospholipid with reference to disodium hydrogen orthophosphate

The chemical shift between disodium hydrogen orthophosphate and phosphoric acid was $-3 \cdot 5$ (Jones \& Katritzky, 1960).

\begin{tabular}{|lccc|}
\hline $\begin{array}{l}\text { Substance and } \\
\text { spectrum type }\end{array}$ & $\begin{array}{c}\text { Resonance width } \\
\text { (start/end, p.p.m.) }\end{array}$ & $\begin{array}{c}\text { Maximum } \\
\text { (p.p.m.) }\end{array}$ & $\begin{array}{c}\text { HHLW* } \\
\text { (p.p.m.) }\end{array}$ \\
\hline RNA & $0 /-16$ & $-7 \cdot 6$ & 7 \\
CPMAS & $-1 /-18$ & $-7 ;-8$ & 7 \\
SPMAS & & & \\
DNA & $0 \cdot 8 /-12$ & $-6 \cdot 8$ & $4 \cdot 8$ \\
CPMAS & $-1 /-12$ & $-7 \cdot 1$ & $4 \cdot 8$ \\
SPMAS & & & \\
$\begin{array}{l}\text { Disodium } \\
\text { hydrogen } \\
\text { orthophosphate }\end{array}$ & $5 /-5$ & 0 & $2 \cdot 7$ \\
CPMAS & $7 /-5$ & 0 & 3 \\
$\begin{array}{l}\text { SPMAS } \\
\text { Phospholipid }\end{array}$ & $-2 /-11$ & $-6 \cdot 7$ & $2 \cdot 9$ \\
SPMAS & & & \\
\hline
\end{tabular}

*HHLW, half-height line width.

resonance at -18 p.p.m. was higher in intensity with an alteration of the excitation pulse $\left(\mathrm{D}_{1}\right)$ to $\pi / 4$ and of the repetitive rate $\left(D_{0}\right)$ to $30 \mu$ s (Fig. 1a) which indicates that this component had a longer relaxation time than those with resonances between 1 and -12 p.p.m. The corresponding CPMAS spectrum displayed a very broad resonance ranging from 1 to -16 p.p.m. with two maxima at -3.2 and -7 p.p.m. (Fig. 1b). These immobilized phosphorus components are reflected in the SPMAS spectrum (Fig. 1a) by a broad peak underneath the five single peaks. The CPMAS spectrum remained the same when dehydrated spores were examined (data not shown). However, in the SPMAS spectrum, phosphorus mobility decreased as a consequence of dehydration (Fig. 1c, d). The SPMAS spectrum of freeze-dried spores was poor, having a high noise-tosignal ratio and only a broad resonance between 100 p.p.m. and -150 p.p.m. (Fig. 1c). This indicated the presence of solely non-mobile molecular phosphorus components in freeze-dried spores and shows by comparison with the SPMAS spectrum of spore slurries (Fig. 1a) that water affects phophorus mobility. Rehydration of freeze-dried spores to a weight increase of $10 \%$ resulted in a significant increase in molecular mobility, shown by narrowing of the broad resonance to one peak with a half-height width of $2 \cdot 7$ p.p.m. (Fig. 1d). An addition of excess water furthered this effect and led to a spectrum identical to that of the native spore preparation (Fig. 1a) with distinct peak maxima and a major peak at -7 p.p.m. having a half-height width of 0.5 p.p.m. Comparison of peaks observed in the ${ }^{31} \mathrm{P}$ SPMAS and CPMAS spectra with those of RNA and DNA suggest that both these are present in NMR spectra of spore samples (Table 1). 3-Phosphoglycerate is a component of spores and is responsible for significant amounts of phosphorus in the core. From our own data and that of Rao et al. (1978), it has a chemical shift of -0.3 p.p.m. after the difference in shift between the reference substance in the two studies of -3.5 p.p.m. (Jones \& Katritzky, 1960; Crutchfield et al., 1962) is taken into account.

\section{High-resolution solid-state ${ }^{13} \mathrm{C}$ NMR spectroscopy}

Molecular mobility in ${ }^{13} \mathrm{C}$ SPMAS NMR spectra increased when excess water was added to spores containing $10 \%$ water (Fig. 2a, b). Results show a considerable mobility in the protein and carbohydrate area at $10 \%$ moisture and an addition of excess water led to increased mobility particularly at $\sim 75$ and 104 p.p.m. where mainly carbohydrates resonate. The corresponding ${ }^{13} \mathrm{C}$ CPMAS spectra (Fig. 2c, d) revealed immobilized carbon components throughout the spectrum and, at 150 p.p.m., the resonance of DPA. Native wet spores displayed no differences in ${ }^{13} \mathrm{C}$ NMR spectra compared to samples which were resuspended in water after freezedrying. The resonance peak of DPA at 150 p.p.m. was identified by Lundin \& Sacks (1988), and in the present study was observed in the ${ }^{13} \mathrm{C}$ CPMAS but never in the SPMAS spectra, suggesting that DPA remained immobilized at all hydration levels. Higher signal intensities were observed in the ${ }^{13} \mathrm{C}$ CPMAS spectrum of spore slurries than in preparations with $10 \%$ water content or freeze-dried spores (data not shown).

\section{STEM}

STEM measurements of freeze-dried and native, hydrated spores were carried out and analysed for significant differences. Results obtained for native and freeze-dried spore dimensions were 1.34 (SD 0.13) and 1.40 (SD 0.14) $\mu \mathrm{m}$ in length, and 0.57 (SD 0.036) and $0.55 \mu \mathrm{m}$ (sD 0.035) in breadth, respectively. Analysis for significance of the differences in size by ANOva revealed that freeze-dried spores were significantly narrower $(P<0 \cdot 0001)$ than fully hydrated spores and also significantly longer $(P<0 \cdot 0028)$. According to the equation for the volume of an equivalent sphere $V_{\mathrm{ES}}=\pi a b^{2} / 6$ (where $V=$ volume, $a=$ length and $b=$ breadth), the volume of the freeze-dried spores was $3 \%$ smaller than that of fully hydrated spores. These results show that hydration affects spore dimensions.

Control experiments on spore slurries after NMR analysis revealed no effects on spore viability and their internal structure when investigated by TEM. Experiments to cut ultrathin sections of freeze-dried spores which were preserved in water-free $\mathrm{OsO}_{4}$ for TEM were not successful because the preservation and fixing of inner spore compartments was not satisfactory. It was therefore not possible to examine TEM sections of freeze-dried spores and compare them with fully hydrated spores to identify changes in internal compartments due to hydration. We could not identify 
(a)
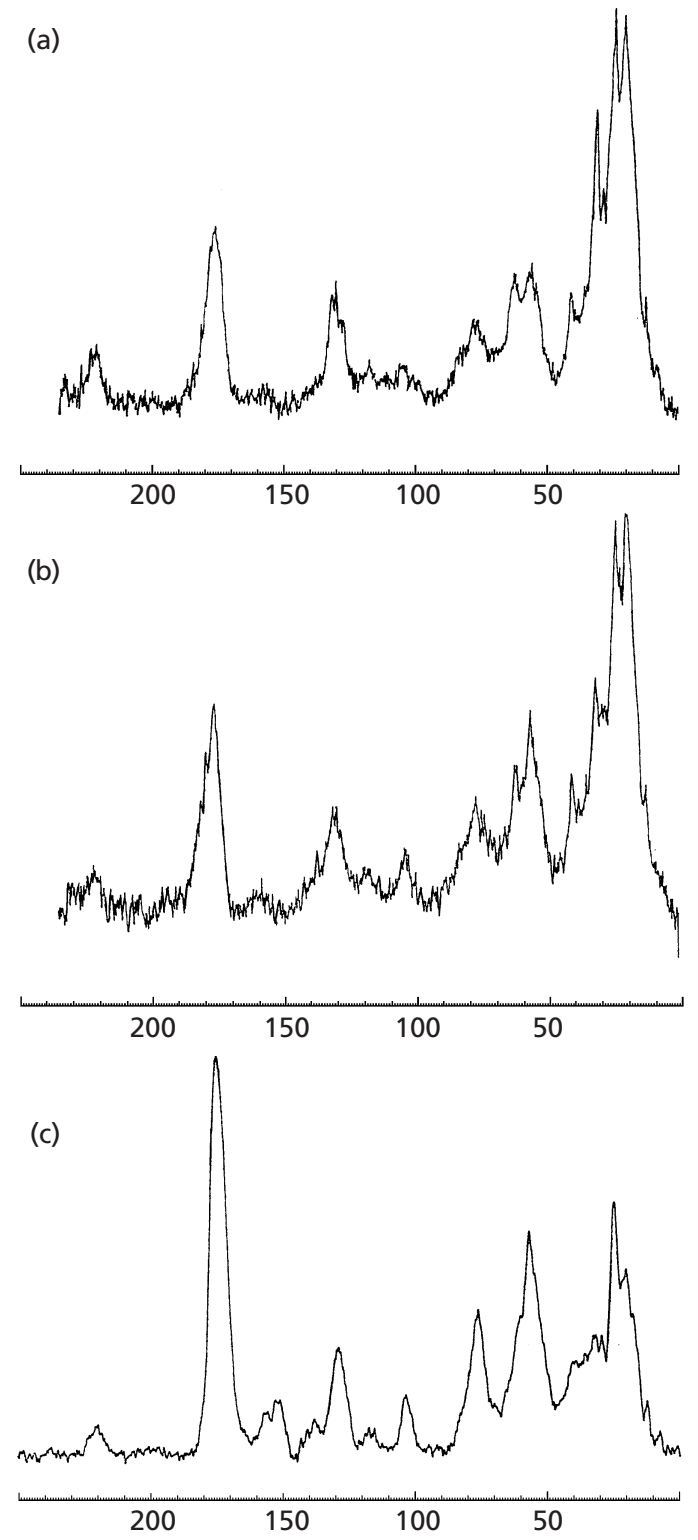

(d)

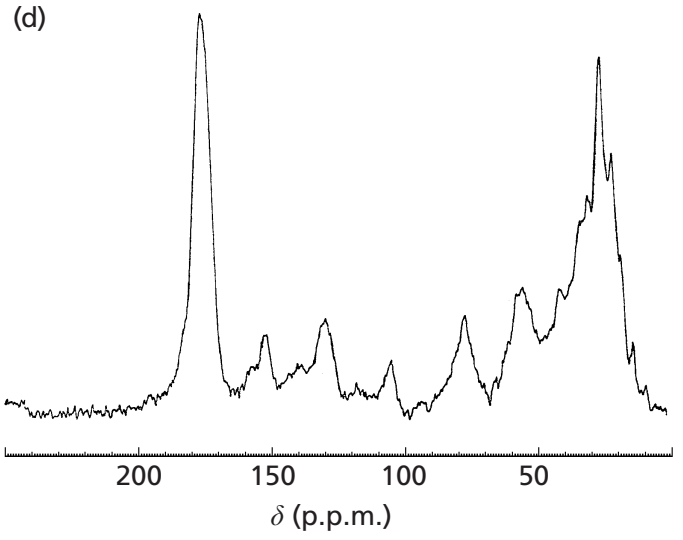

which compartments of the spore increased in volume as a consequence of water adsorption.

\section{DISCUSSION}

${ }^{31} \mathrm{P}$ NMR analyses revealed that in the SPMAS spectrum mobile and immobile phosphorus components resonated, whereas in the CPMAS spectrum only crosspolarizable (immobilized) phosphorus appeared. These observations were in agreement with those of Rasmussen et al. (1997). The ${ }^{31} \mathrm{P}$ CPMAS spectra of $B$. subtilis spores were not dependent on hydration, indicating that a fraction of phosphorus-containing components remained immobile even in a spore suspension in water. On the other hand, line narrowing was evident in SPMAS spectra with increasing hydration. Total mobilization of phosphorus was not achieved by water addition, which means that phosphorus-containing components remained partly immobilized. RNA, DNA, a phospholipid and 3-phosphoglycerate had chemical shifts similar to the resonances which were observed in the spectra of spores, whereby RNA, DNA and the phospholipid resonated at $\sim-7$ p.p.m. and 3phosphoglycerate at $\sim-0.5$ p.p.m. The chemical shifts of disodium hydrogen orthophosphate and of phosphoric acid were not observed in our spore spectra, but an assignment of resonances to internal orthophosphate was reported by Shibata et al. (1984). One reason for this discrepancy could be that these chemical shifts are $\mathrm{pH}$ dependent (Nicolay, 1992; Shibata et al., 1984) and in our spectra they were shifted by the proton concentration in the core region, which is between $\mathrm{pH} 6.3$ and 6.5 for dormant spores (Massey Swerdlow et al., 1981), into the main bulk of resonances. Our phosphorus spectra differed significantly from those shown by Shibata et al. (1984), who only obtained resolvable spectra with two or three peaks by addition of EDTA. Presumably, the EDTA removed diamagnetic and paramagnetic polyvalent metal ions (Henderson et al., 1974). This may have been achieved in our investigation by repetitive washing of spores in distilled water prior to NMR analysis.

Phosphorus is mainly located in the core (Nishihara et al., 1980; Stewart et al., 1980) and changes in molecular mobility due to addition or removal of water show that water can diffuse between the core and the environment. On the other hand, no molecular mobility increase was observed for DPA, another core-specific component when spores were hydrated. DPA was observed in our investigation in the ${ }^{13} \mathrm{C}$ CPMAS spectrum but never in a SPMAS spectrum, in agreement with the results of Lundin \& Sacks (1988). These data, in combination with the results we obtained for phosphorus mobility, suggest that DPA could exist in the core immobilized in

weight increase) freeze-dried, phase-bright spores of $B$. subtilis PBS 357 lux ${ }^{+}$(c) and ${ }^{13} \mathrm{C}$ CPMAS NMR spectrum of freeze-dried, phase-bright spores of $B$. subtilis PBS 357 lux $^{+}$supplemented with excess water (d).
Fig. 2. ${ }^{13} \mathrm{C}$ SPMAS NMR spectrum of rehydrated (10\% weight increase) freeze-dried, phase-bright spores of $B$. subtilis PBS 357 $\operatorname{lux}^{+}(a),{ }^{13}$ C SPMAS NMR spectrum of freeze-dried, phase-bright spores of $B$. subtilis PBS 357 lux $^{+}$supplemented with excess water (b), ${ }^{13} \mathrm{C}$ CPMAS NMR spectrum of rehydrated $(10 \%$ 
a water-insoluble network. A model which postulates the occurrence of an insolubly gelled core with crosslinking between macromolecules to form a high-polymer matrix with entrapped free water has been suggested by Black \& Gerhardt (1962). DPA was reported to bind covalently to specific macromolecules (Matano et al., 1993) and could therefore be involved in the formation of a stable network in which immobilized phosphorus might be integrated. Our results would not be consistent with the assumption that water is completely entrapped in a network because we observed exchange of water with the environment.

We observed a better cross-polarization of ${ }^{13} \mathrm{C}$ components when more water was present, which was surprising since higher intensities would be expected at lower moisture contents. Similar effects were however described for low-moisture polysaccharides by Cooke et al. (1996). Hydration studies analysed by ${ }^{13} \mathrm{C}$ NMR revealed a dependence on the water concentration and a considerable mobility in the cortex and proteins of dormant, fully hydrated spores. A region related to polysaccharides and carbohydrates at $\sim 75$ and 104 p.p.m. (Kalichevsky et al., 1992) and B. subtilis cell walls (Forrest et al., 1991) displayed mobility changes when native spores and preparations with $10 \%$ water were compared. This could indicate increasing hydration of the cortex.

Our data also revealed a strong effect of hydration on spore dimensions and showed that the breadth and length of spores changed significantly. The dormant spore structure displayed some degree of flexibility but total hydration was prevented by the structure since the spores remained phase-bright throughout. Similar observations were described by Watt (1981), who determined water vapour sorption isotherms of intact spores of Bacillus stearothermophilus and fractions (coat, coat and cortex, core). At low humidities the water content of intact spores was the sum of the water contents of the fractions, but the coat played a determining role in restricting swelling of the spore near saturation. We did not observe adhesion of material at the outer electron-dense coat during TEM investigations of spore sections. Our spore harvests displayed a high purity and were nearly $100 \%$ liberated from the mother cell. We do not believe that the change in size could be explained by mother cell wall material which was attached to the spore.

A final conclusion regarding the mechanism which keeps dormant spores phase-bright in water needs further investigation since it seems to be complex, and a combination of functions associated with several spore compartments is probably involved.

\section{ACKNOWLEDGEMENTS}

The authors thank A. H. Darke for NMR analyses and A. C. Weaver for support during electron microscopy. This work was funded by a European Community Marie Curie Research Training Grant in the Framework of the FAIR Programme (FAIR CT 975014).

\section{REFERENCES}

Ablett, S., Darke, A. H., Lillford, P. J. \& Martin, D. R. (1999). Glass formation and dormancy in bacterial spores. Int J Food Sci Technol 34, 59-69.

Beaman, T. C. \& Gerhardt, P. (1986). Heat resistance of bacterial spores correlated with protoplast dehydration, mineralization, and thermal adaptation. Appl Environ Microbiol 52, 1242-1246.

Beaman, T. C., Koshikawa, T., Pankratz, H. S. \& Gerhardt, P. (1984). Dehydration partitioned within core protoplast accounts for heat resistance of bacterial spores. FEMS Microbiol Lett 24, 47-51.

Bendall, M. R. \& Gordon, R. E. (1983). Depth and refocusing pulses designed for multipulse NMR with surface coils. J Magnet Reson 53, 365-385.

Black, S. H. \& Gerhardt, P. (1962). Permeability of bacterial spores. IV. Water content, uptake, and distribution. J Bacteriol 83, 960-967.

Bradbury, J. H., Foster, J. R., Hammer, B., Lindsay, J. \& Murrell, W. G. (1981). The source of the heat resistance of bacterial spores. Study of water in spores by NMR. Biochim Biophys Acta 678, 157-164.

Cooke, D., Gidley, M. J. \& Hedges, N. D. (1996). Thermal properties of polysaccharides at low moisture. II. Molecular order and control of dissolution temperature in agar. $J$ Therm Anal 47, 1485-1498.

Crutchfield, M. M., Callis, C. F., Irani, R. R. \& Roth, G. C. (1962). Phosphorus nuclear magnetic resonance studies of ortho and condensed phosphates. Inorg Chem 1, 813-817.

Dixon, K. R. (1987). Phosphorus to bismuth. In Multinuclear NMR, pp. 369-402. Edited by J. Mason. New York: Plenum.

Dixon, W. T., Schaeffer, J., Sefcik, M. D., Stejskal, E. O. \& McKay, R. A. (1982). Total suppression of sidebands in CPMAS C-13 NMR. J Magnet Reson 49, 341-345.

Errington, J. (1993). Bacillus subtilis sporulation: regulation of gene expression and control of morphogenesis. Microbiol Rev 57, 1-33.

Forrest, T. M., Wilson, G. E., Pan, Y. \& Schaefer, J. (1991). Characterization of cross-linking of cell walls of Bacillus subtilis by a combination of magic-angle spinning NMR and gas chromatography-mass spectrometry of both intact and hydrolyzed ${ }^{13} \mathrm{C}$ - and ${ }^{15} \mathrm{~N}$-labeled cell-wall peptidoglycan. J Biol Chem 266, 24485-24491.

Gaillard, S., Leguerinel, I. \& Mafart, P. (1998). Model for combined effects of temperature, $\mathrm{pH}$ and water activity on thermal inactivation of Bacillus cereus spores. J Food Sci 63, 887-889.

Gould, G. W. (1977). Recent advances in the understanding of resistance and dormancy in bacterial spores. J Appl Bacteriol 42, 297-309.

Gould, G. W. \& Dring, D. J. (1974). Mechanisms of spore heat resistance. Adv Microb Physiol 2, 137-164.

Gould, G. W. \& Dring, G. J. (1975). Heat resistance of bacterial endospores and concept of an expanded osmoregulatory cortex. Nature 258, 402-405.

Henderson, T. O., Glonek, T. \& Myers, T. C. (1974). Phosphorus-31 nuclear magnetic resonance spectroscopy of phospholipids. Biochemistry 13, 623-628.

Hill, P. J., Hall, L., Vinicombe, D. A., Soper, C. J., Setlow, P., Waites, W. M., Denyer, S. \& Stewart, G. S. A. B. (1994). Bioluminescence and spores as biological indicators of inimical processes. J Appl Bact 76 (suppl.), S129-S134.

Johnstone, K., Ellar, D. J. \& Appleton, T. C. (1980). Location of 
metal ions in Bacillus megaterium spores by high-resolution electron probe x-ray microanalysis. FEMS Microbiol Lett 7, 97-101.

Jones, R. A. Y. \& Katritzky, A. R. (1960). A correlation between the degree of ionization of phosphates and the frequency of phosphorus magnetic resonance. J Inorg Nucleic Chem 15, 193-194.

Kalichevsky, M. T., Jaroszkiewicz, E. M., Ablett, S., Blanshard, J. M. V. \& Lillford, P. J. (1992). The glass transition of amylopectin measured by DSC, DMTA and NMR. Carbohydr Polym 18, 77-88.

Kozuka, S., Yasuda, Y. \& Tochikubo, K. (1985). Ultrastructural localization of dipicolinic acid in dormant spores of Bacillus subtilis by immunoelectron microscopy with colloidal gold particles. J Bacteriol 162, 1250-1254.

Lenz, G. \& Gilvarg, C. (1973). Dipicolinic acid location in intact spores of Bacillus megaterium. J Bacteriol 114, 455-456.

Leuschner, R. G. K., Weaver, A. C. \& Lillford, P. J. (1999). Rapid particle size distribution analysis of Bacillus suspensions. Colloids Surf B 13, 47-57.

Lindsay, J. A. \& Murrell, W. G. (1986). Solution spectroscopy of dipicolinic acid interaction with nucleic acids: role in spore heat resistance. Curr Microbiol 13, 255-259.

Lindsay, J. A., Beaman, T. C. \& Gerhardt, P. (1985). Protoplast water content of bacterial spores determined by buoyant density sedimentation. J Bacteriol 163, 735-737.

Loshon, C. A. \& Setlow, P. (1993). Levels of small molecules in dormant spores of Sporosarcina species and comparison with levels in spores of Bacillus and Clostridium species. Can J Microbiol 39, 259-262.

Lundin, R. E. \& Sacks, L. E. (1988). High-resolution solid-state ${ }^{13} \mathrm{C}$ nuclear magnetic resonance of bacterial spores: identification of the alpha-carbon signal of dipicolinic acid. Appl Environ Microbiol 54, 923-928.

Maeda, Y., Fujita, T., Sugiura, Y. \& Koga, S. (1968). Physical properties of water in spores of Bacillus megaterium. J Gen Appl Microbiol 14, 217-226.

Massey Swerdlow, B., Setlow, B. \& Setlow, P. (1981). Levels of $\mathrm{H}^{+}$ and other monovalent cations in dormant and germinating spores of Bacillus megaterium. J Bacteriol 148, 20-29.

Matano, Y., Yasuda, Y. \& Tochikubo, K. (1993). Evidence that dipicolinic acid is covalently bound to specific macromolecules in spores of Bacillus subtilis. FEMS Microbiol Lett 109, 189-194.

Moir, A. \& Smith, D. A. (1990). The genetics of bacterial spore germination. Annu Rev Microbiol 44, 531-553.
Murrell, W. G. (1969). Chemical composition of spores and spore structure. In The Bacterial Spore, pp. 215-273. Edited by G. W. Gould \& A. Hurst. London: Academic Press.

Nakashio, S. \& Gerhardt, P. (1985). Protoplast dehydration correlated with heat resistance of bacterial spores. J Bacteriol 162, 571-578.

Nicolay, K. (1992). Application of ${ }^{31} \mathrm{P}$ NMR in the study of microbial metabolism. Trends Food Sci Technol 3, 225-230.

Nishihara, T., Ichikawa, T. \& Kondo, M. (1980). Location of elements in ashed spores of Bacillus megaterium. Microbiol Immunol 24, 495-506.

Rao, D. B. N., Cohn, M. \& Scopes, R. K. (1978). ${ }^{31}$ P NMR study of bound reactants and products of yeast 3-phosphoglycerate kinase at equilibrium and the effect of sulfate ion. J Biol Chem 253, 8056-8060.

Rasmussen, L. K., Sørensen, E. S., Petersen, T. E., Nielsen, N. C. \& Thomsen, J. K. (1997). Characterization of phosphate sites in native ovine, caprine, and bovine casein micelles and their caseinomacropeptides: a solid-state phosphorus-31 nuclear magnetic resonance and sequence and mass spectrometric study. J Dairy Sci 80, 607-614.

Santo, L. Y. \& Doi, R. H. (1974). Ultrastructural analysis during germination and outgrowth of Bacillus subtilis spores. J Bacteriol 120, 475-481.

Setlow, P. (1994). Mechanisms which contribute to the long-term survival of spores of Bacillus species. J Appl Bacteriol 76, 49S-60S.

Shibata, H., Asakura, M. \& Tani, I. (1984). An approach to estimation of internal $\mathrm{pH}$ of bacterial spores by ${ }^{31} \mathrm{P}$ nuclear magnetic resonance. Jpn J Bacteriol 39, 749-755.

Shibata, H., Yamashita, S., Ohe, M. \& Tani, I. (1986). Laser raman spectroscopy of lyophilized bacterial spores. Microbiol Immunol 30, 307-313.

Stewart, M., Somlyo, A. P., Somlyo, A. V., Shuman, H., Lindsay, J. A. \& Murrell, W. G. (1980). Distribution of calcium and other elements in cryosectioned Bacillus cereus $\mathrm{T}$ spores, determined by high-resolution scanning electron probe x-ray microanalysis. J Bacteriol 143, 481-491.

Watt, I. C. (1981). Water vapor adsorption by Bacillus stearothermophilus endospores. In Sporulation and Germination, pp. 253-255. Edited by H. S. Levinson, A. L. Sonenshein \& D. J. Tipper. Washington, DC: American Society for Microbiology.

Received 28 June 1999; revised 24 September 1999; accepted 27 September 1999. 